\title{
Influencia de la crisis Covid-19 en los hábitos de consumo de estudiantes universitarios de Arequipa
}

\author{
Influence of the Covid-19 crisis on the consumption habits of university \\ students in Arequipa
}

Sofía Camila Hinojosa Paz

Universidad Católica San Pablo, Arequipa, Perú • sofia.hinojosa@ucsp.edu.pe

Nathaly Gianella Bernedo Gómez

Universidad Católica San Pablo, Arequipa, Perú • nathaly.bernedo@ucsp.edu.pe

\section{Resumen}

La presente investigación muestra la influencia de la crisis provocada por el Covid-19 en los hábitos de consumo de estudiantes universitarios arequipeños, con el objetivo de conocer de qué manera y qué elementos de los hábitos de consumo se vieron influenciados, y cómo variaron antes y durante la pandemia y las perspectivas para el futuro. Para hacer este estudio se tomaron en cuenta antecedentes de otras investigaciones de la crisis por Covid-19 realizadas en diferentes países y distintos grupos etarios. Luego, se recogieron datos de una muestra de 382 universitarios y se analizaron de manera descriptiva los cambios en las necesidades del consumidor, la actitud de consumo, el lugar de compra y las distintas categorías de productos y servicios que se vieron influenciadas por esta crisis. El estudio encontró que, a partir de la pandemia, los universitarios arequipeños realizaron compras más racionales, se preocuparon por la búsqueda de información para la toma de decisiones de compra, y priorizaron la salud por encima de la necesidad social y de autoestima. Algunos hábitos adquiridos en la pandemia permanecerán, como las compras online y la educación virtual.

Palabras clave: crisis, pandemia, hábitos de consumo, comportamiento del consumidor.

illustro • Universidad Católica San Pablo, Arequipa • Vol. 12, 2021, 79-102 • e-ISSN 2710-2440

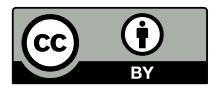




\begin{abstract}
The present investigation shows the influence of the Covid-19 crisis on the consumption habits of Arequipa university students, with the objective of knowing in what way and what elements of the consumption habits were really influenced and how they varied before and during the pandemic and the perspectives for the future. This study took into account background information from other investigations of the Covid-19 crisis carried out in different countries and different age groups. We then collected data from a sample of 382 university students and descriptively analyzed changes in consumer needs, consumer attitudes, place of purchase, and the different categories of products and services that were influenced by this crisis. The study found that the pandemic led Arequipa's university students to make more rational purchases, were more concerned about the search for information for making purchase decisions, and prioritized health over social need and self-esteem. Some habits acquired will remain after the pandemic is controlled, such as more online shopping and virtual education.
\end{abstract}

Keywords: crisis, pandemic, consumption habits, consumer behavior.

\title{
1. Introducción
}

Actualmente el mundo pasa por una crisis ocasionada por la pandemia del Covid-19 que, siendo inicialmente una crisis sanitaria, también dio paso a una crisis económica. En el Perú, la tasa de desempleo aumentó aproximadamente de $3 \%$ en 2019 a $6.2 \%$ en 2020 (International Labour Organization, 2020). Particularmente, en la ciudad de Arequipa, donde se realizó el presente estudio, se identificó que la economía también se vio claramente afectada. La producción presentó una fuerte caída (-32.7\%), con la contracción en la mayoría de sectores, como minería, manufactura, construcción y comercio (Cámara de Comercio e Industria de Arequipa, 2020) y afectó a las personas que dependen directa e indirectamente de los mismos. De acuerdo con el Instituto Peruano de Economía (2021), durante el año 2020 la tasa de pobreza en la zona sur del país (Arequipa, Cusco, Puno, Apurímac, Moquegua y Tacna) se elevó a 31\%.

La pandemia del Covid-19 llevó a un cambio radical en los hábitos de compra, tanto a nivel de los canales retail como en los comportamientos de los compradores a nivel global (Euromonitor International, 2020).

En este contexto se considera importante investigar, en la región Arequipa, qué hábitos de consumo sufrieron variaciones y de qué manera, principalmente cómo la actual crisis afectó los hábitos de consumo de los jóvenes estudiantes. Para esta investigación se tomó como muestra a estudiantes universitarios de pregrado de las universidades más antiguas y establecidas en la ciudad de Arequipa. Se eligió a universitarios por ser una población poco analizada como consumidor en esta crisis, y con la motivación de conocer los impactos en las compras de categorías de productos y servicios que resaltan en el grupo etario de los universitarios.

En la línea del marketing, los «hábitos de consumo» se definen como: «Aquellas formas con que procede el consumidor al momento de realizar sus compras, los hábitos se logran a 
través de la repetición seguida de actos originados por costumbres, gustos, preferencias, usos e incluso tendencias instintivas» (Herrero, 2007).

Las compras se pueden clasificar en compras impulsivas y compras racionales. La compra impulsiva viene determinada por un impulso, sin mayor esfuerzo racional en el proceso de compra (Quintanilla et al., 1998). Lo contrario pasa en las compras racionales, puesto que son compras más reflexivas, es decir, determinando la relación entre el costo y el beneficio de los bienes a adquirir (Quintanilla, 2010).

Las actitudes que los consumidores toman a la hora de realizar el proceso de compra vienen dadas por diferentes factores, tanto externos como internos. Truong (2010) menciona que los factores internos se relacionan con el sentido de pertenencia; las personas buscan encajar, ser elogiadas, pertenecer a un círculo social.Y existen otros factores, como disponibilidad, tendencia, moda y estacionalidad.

Los factores internos hacen referencia a un estímulo propio de los consumidores, quienes buscan la forma de satisfacer adecuadamente sus necesidades. Se trata del «comportamiento suscitado por necesidades y dirigido hacia la obtención de un fin; la motivación es un comportamiento o actitud del consumidor para conseguir ya sea un bien o un servicio» (Fischer de la Vega y Espejo Callado, 2011, p. 80).

La pandemia ha modificado los hábitos de consumo. En el contexto de la crisis por el Covid-19 se encontró que, en primer lugar, debido a las alteraciones en la economía de los consumidores y la preocupación por el contagio del virus al momento de hacer las compras, se priorizó la satisfacción de necesidades básicas con el consumo de productos de primera nece- sidad, dejando de adquirir productos y servicios no esenciales. Así, «las categorías discrecionales, como los puntos de venta de servicios de comida, las tiendas de ropa y los grandes almacenes, se vieron muy afectadas durante la crisis y su recuperación ha sido lenta» (Huang et al., 2020, p. 1). Por el contrario, «los supermercados, tiendas de conveniencia y farmacias experimentaron un aumento en la actividad durante la crisis, ya que los consumidores se abastecieron de artículos esenciales y cocinaron en casa» (Huang et al., 2020, p. 1).

Asimismo, a raíz de la pandemia, los consumidores adoptaron hábitos de compra más responsables e informados, analizaron los gastos y evitaron el despilfarro de dinero. En general, los consumidores se volvieron más conscientes de lo que compraban y se esforzaron por limitar el desperdicio de alimentos, comprar con mayor consciencia de costos y optar por opciones más sostenibles (Wright y Blackburn, 2020). Junto con el análisis y recorte de gastos, los consumidores fueron más sensibles al cambio de precios y, con ello, los atributos de calidad pasaron a un segundo plano.

En muchos sectores, desde el transporte aéreo hasta los bienes duraderos, las fuertes caídas de la demanda, el exceso de capacidad y una mayor sensibilidad a los precios están convergiendo para hacer bajar los precios y destruir el valor. Muchos clientes piden descuentos. (Abdelnour et al., 2020).

Otro cambio importante en los hábitos de consumo durante la pandemia se dio en el lugar de compra. Debido a las medidas sanitarias para evitar la expansión de la enfermedad, las personas tuvieron que adquirir sus productos esenciales con mayor énfasis en el mercado local. Los consumidores notaron que estas decisiones 
trajeron consigo varios beneficios, como el apoyo al restablecimiento de la economía local (Zierlein et al., 2020). Las personas perciben mayor seguridad al conocer el origen de los productos que desean adquirir. Los productores locales poseen cadenas de distribución más cortas y por ello el peligro de contagio se hace menor, esto aporta seguridad a los consumidores. $« \mathrm{El}$ deseo de comprar localmente se refleja tanto en los productos que compran los consumidores (por ejemplo, de origen local, artesanales) como en la forma en que compran (apoyo a tiendas comunitarias)» (Wright y Blackburn, 2020).

En cuanto a las compras en línea, se observó que «la mayoría de los productos han experimentado un crecimiento de más del $10 \%$ en su base de clientes en línea durante la pandemia y muchos consumidores consideran seguir comprando en línea incluso cuando las tiendas físicas vuelvan a abrir» (Arora et al., 2020).

Las restricciones fronterizas también trajeron consigo cambios en los hábitos de consumo, ya que la cadena de distribución de muchos productos se vio interrumpida. Al no encontrar su marca de preferencia en su minorista elegido, los consumidores se vieron obligados a probar nuevas marcas. Ello quebró en muchas ocasiones la lealtad de marca de los consumidores. Muchos consumidores probaron una marca diferente $o$ compraron en un minorista diferente durante la crisis. Se espera que estos cambios vayan más allá del tiempo de pandemia (Arora et al., 2020).

En la presente crisis la salud cobró mayor importancia, se forjaron hábitos durante la pandemia y para la posteridad como el uso de mascarillas, que hasta el momento es obligatorio en los lugares de compra físicos, así como la desinfección de los productos comprados. La población peruana incrementó su gasto en productos de limpieza para el hogar y salud, el cual en su mayoría se mantendrá o aumentará con el paso de los meses. (Sagara et al., 2020).

En cuanto a los productos entregados por delivery, se buscó que estos cumplieran con ciertas medidas de bioseguridad, lo que incrementó el uso de envases de plástico en los que eran entregados. Como consecuencia, «se prevé que el tamaño del mercado mundial de envases de plástico crezca de USD 909.2 mil millones en 2019 a 1012.6 mil millones en 2021, a una tasa de crecimiento anual compuesta del $5.5 \%$, principalmente debido a la respuesta a la pandemia» (Adyel, 2020). Estas dos últimas tendencias marcan el factor ambiental de esta crisis.

En líneas anteriores se ha visto cómo la crisis provocada por el Covid-19 ha afectado en los hábitos de consumo del proceso de compra de los consumidores, es decir, el cómo realizan las compras; sin embargo, también se debe realizar el análisis en las categorías de productos, es decir, el qué se compra. Como primera categoría se desarrolla los insumos alimenticios, en la modalidad de consumo, y es que durante la pandemia los consumidores preferían preparar los alimentos en el hogar (Arora et al., 2020), antes que pedir el delivery de algún restaurante. Este comportamiento se explica también por las diferentes restricciones y el confinamiento que era una barrera para el desarrollo total de esta modalidad. En el transcurso de la pandemia varias restricciones se levantaron, dando pie a que el servicio a domicilio tenga un mayor auge; sin embargo, aun después de la pandemia los consumidores preferirán preparar sus alimentos dentro del hogar (Quelart, 2020).

Durante la pandemia se ha apreciado que las principales prioridades para los consumidores son la salud y la alimentación; como segunda 
prioridad, la aceptación social y, con ello, aspectos de estética o de sentido de pertenencia. Es por ello que en varios países del mundo se ha reducido el uso de los artículos de belleza, pues no es una prioridad durante la época de crisis (Arora et al., 2020). Se espera que, al volver a la normalidad, los consumidores retornen a sus hábitos de compra, principalmente en productos para uñas y ojos (Medina, 2020).

Cuando se dio a conocer la pandemia por Covid19 , varios países optaron por el confinamiento como principal medida de prevención; por tal motivo, la adquisición de ropa, calzado y accesorios tuvo una caída del $30 \%$ aproximadamente (Arora et al., 2020). Esta categoría de consumo se verá modificada después de la pandemia; se espera que prevalezcan factores como la calidad y durabilidad de los productos (Gallego, 2020).

Durante el confinamiento surgió una variación en la categoría de productos y servicios de entretenimiento. El entretenimiento dentro del hogar se tradujo en compras como juegos de mesa, juegos en línea, libros, streaming, etc. (Arora et al., 2020). Para después de la pandemia no se prevé un pronto retorno al entretenimiento fuera de casa; este será progresivo. Los principales sectores afectados son los restaurantes, los cines y las discotecas (Solana, 2020).

Dentro de la categoría de servicios también se han identificado cambios, tales como los cursos en línea, que durante la pandemia obtuvieron mayor confiabilidad para los diferentes usuarios. Por la necesidad de crecimiento personal y profesional, el público tuvo que recurrir a la virtualidad (Ipsos, 2020, p. 59). Después de la pandemia esta categoría se mantendrá como nuevo hábito nacido de la crisis, pues los usuarios han podido presenciar los beneficios que le ofrecen estos servicios (Ipsos, 2020, p. 59).
Como consecuencia de la pandemia, los desplazamientos de personas se vieron afectados. Además del cierre de fronteras, con el consiguiente impacto en los viajes internacionales, se alteró el transporte urbano, con un mayor empleo de bicicletas, motos y autos particulares (Arora et al., 2020). En la medida en que se controle la pandemia, los viajes se retomarán de manera progresiva; algunos de los nuevos comportamientos probablemente persistan en el tiempo, como el uso de la bicicleta, por presentar beneficios como el distanciamiento social y ser un medio ecoamigable (Maiztegui, 2020).

El objetivo de esta investigación es identificar la influencia de la crisis Covid-19 en los hábitos de consumo, en cuanto a las necesidades del consumidor, actitud de compra, lugar de compra y categorías de productos de estudiantes universitarios de Arequipa. Esta investigación describe la influencia de la crisis Covid-19 en los hábitos de consumo, que es revelada por medio de la revisión teórica y la aplicación de encuestas a los estudiantes de la muestra.

\section{Metodología}

La presente investigación se realizó con datos cuantitativos. El estudio tomó como unidad de análisis a jóvenes universitarios de pregrado de la ciudad de Arequipa. Se eligió este grupo de la población pues son ellos quienes saldrán al campo laboral, en una nueva normalidad, con factores como el tteletrabajo, y enfrentarán la falta de empleo ocasionada por la crisis, lo cual genera incertidumbre en los jóvenes entre los 15 y 29 años (Ruis, 2020).

Los jóvenes universitarios, como consumidores, son una población poco analizada en esta crisis, y surge la necesidad de conocer los impactos en categorías de productos y servicios que 
son propios sobre todo en este grupo etario, como lo son el entretenimiento, la belleza y los viajes. En cuanto al entretenimiento fuera del hogar, fueron los jóvenes universitarios los más afectados con el cierre de discotecas, bares y cines, a causa de la pandemia. Respecto a los juegos en línea, 43\% de los adolescentes juegan en línea frente a un 14\% de los adultos (Ipsos, 2020, p. 1). En la categoría belleza se encontró que «los estudiantes usan más maquillaje y tratamientos faciales que aquellos que trabajan» (Suito, 2020). Por lo que se busca identificar los cambios que ocurrieron en el consumo de estos productos durante la pandemia y los que podrían ocurrir después de ella (Bernedo e Hinojosa, 2021). Adicionalmente, son los jóvenes quienes en la actualidad están mayormente expuestos a las tecnologías en cuanto a la búsqueda de información, métodos de pago y compras en línea. Los jóvenes tienen una exposición

mayor a medios y plataformas de comunicación, tales como redes sociales, web de noticias, plataformas de streaming de video y música, así como podcasts, y, en cuanto a la televisión, están tan expuestos como los adultos de 35 a 59 años (Ipsos, 2020). Lara y Ortega (2016, p. 71) comentan lo siguiente:

Los jóvenes de la Generación Z están habituados a un consumo online en el sentido más amplio de la palabra: compran cada vez más a través de los canales digitales, pero consumen también a través de estos mismos medios todo tipo de informaciones, opiniones, consejos, que les ayudan a crear sus propias opiniones y, por supuesto, a tomar decisiones de compra, decisiones que les pueden inducir a adquirir un determinado producto o servicio, pero también les pueden hacer desistir de hacerlo.
La generación $\mathrm{Z}$ es la que más consume en el área digital: «85\% de los jóvenes-adultos son digitales» (Ipsos, 2020, p. 1). En cuanto a la categoría viajes, los universitarios son de interés para esta investigación, ya que, «en el sector turismo de nuestro país, tanto interno como receptivo, [...] aquel grupo que se encuentra entre los 18 y 34 años de edad, es el de mayor crecimiento» (Ministerio de Comercio Exterior y Turismo, 2014). Y «los segmentos de más rápida recuperación para el turismo local en Perú serían los millennials y centennials» (PromPerú, 2020).

El estudio tuvo como principal fuente de recolección de datos a las universidades de la ciudad de Arequipa, que cuenta con una población de 47,609 universitarios. De esta población se extrajo una muestra de 382 universitarios, que corresponde a un margen de error del 5\% y un nivel de confianza del 95\% (Bernedo y Hinojosa, 2021). El principal objetivo es el de identificar la influencia de la crisis Covid-19 en los hábitos de consumo de universitarios de Arequipa. La pandemia del Covid-19 derivó en una crisis, «situación anormal en la que se tienen que tomar decisiones importantes en corto tiempo» (Shaluf et al., 2019); puede ser catalogada como una crisis no solo sanitaria, sino también económica, social y ambiental. Se analizan los efectos que ha producido en los hábitos de consumo o formas que utilizan los consumidores al comprar (Herrero Ortiz, 2007). Los hábitos se logran mediante la repetición y luego mediante el comportamiento resultante; pueden darse a partir de costumbres, gustos, preferencias, usos e incluso tendencias instintivas. Las variables son medidas a partir de diferentes escalas, tales como la escala de Likert, la escala de diferencial semántico, la escala de intención de comportamiento y la escala ordinal por rangos. La recolección de 
datos se dio tanto con fuentes primarias (cuestionario) como secundarias (revisión de literatura). La técnica que se emplea es la encuesta (con preguntas dicótomas, de alternativa múltiple y de jerarquización).

\section{Resultados}

Datos de control: La mayoría de los encuestados estuvieron en un rango de edad de 18 a 24 años (79.32\%), mayoritariamente mujeres (68.32\%). En cuanto a las universidades, se cumplió con cuotas de encuestados por cada universidad proporcionalmente al número de matriculados en cada universidad: 53.69\% (206) de la Universidad Nacional de San Agustín, 26.18\% (100) de la Universidad Católica Santa María y 19.90\% (76) de la Universidad Católica San Pablo.

En cuanto a si dejaron de comprar algunas categorías de productos por temor al contagio, se puede ver que un gran porcentaje de estudiantes está de acuerdo con esta afirmación (74.6\%). Esto responde a una actitud de compra más responsable, tanto para salvaguardar sus medios económicos como para evitar exponerse al contagio. En respuesta a esto: «Los minoristas de productos no esenciales, como la ropa y el calzado, se enfrentan a una caída significativa de las ventas y están teniendo que adoptar nuevas formas de llegar e involucrar a los clientes que están comprando desde su casa, sólo para mantenerse» (Barrera et al., 2021, p. 14).

\section{Figura 1}

Cese de compras de categorías de productos

Durante la pandemia dejó de comprar ciertas categorías de productos y servicios (ropa, cosméticos, viajes) por temor al contagio

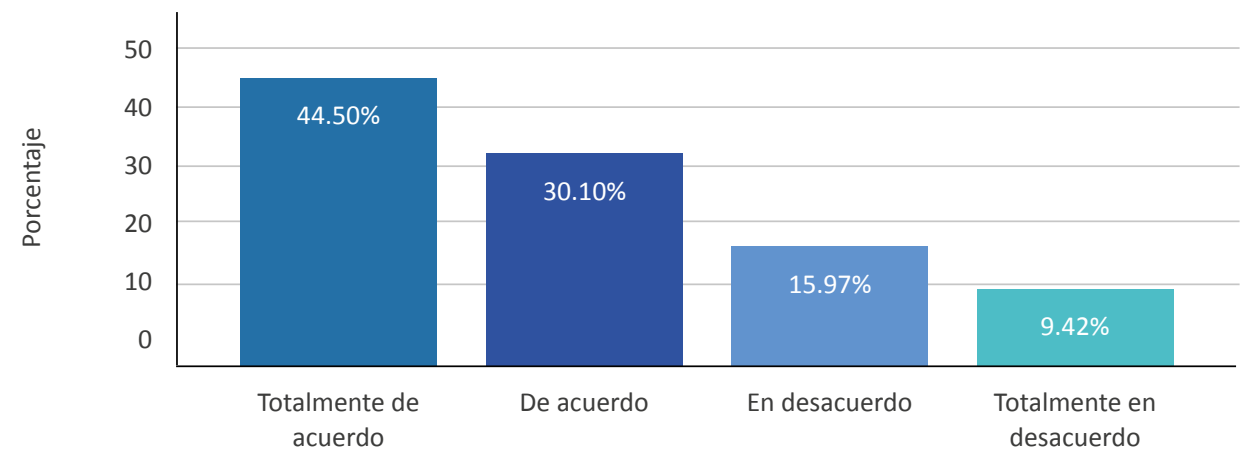

Nota. Elaboración propia. 


\section{Figura 2}

Búsqueda de información sobre productos

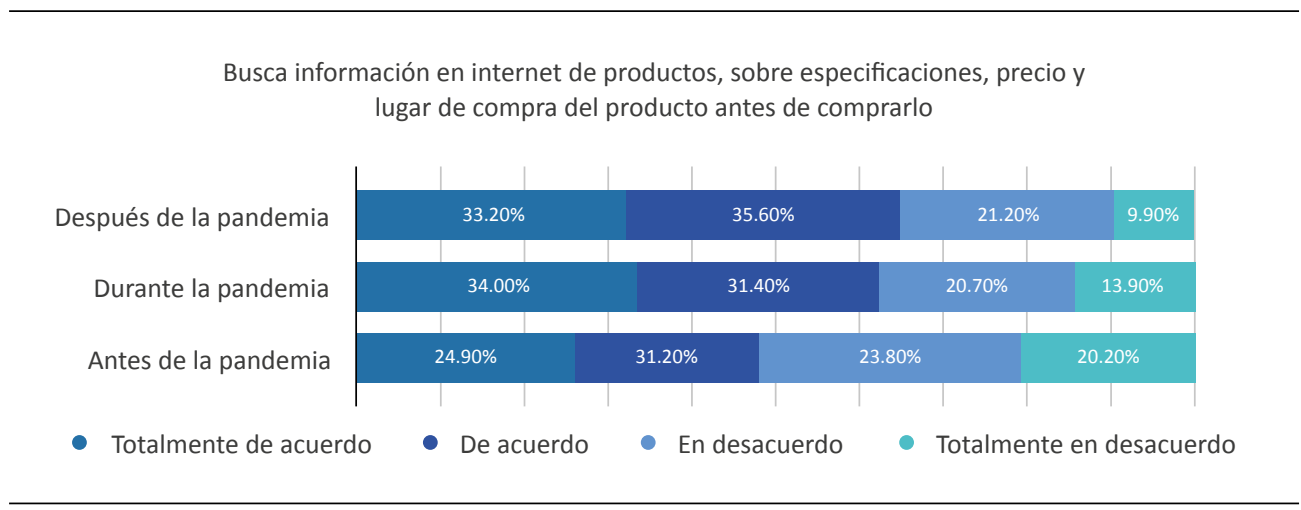

Nota. Elaboración propia.

Los estudiantes buscan información antes de comprar. En los tres tiempos analizados, la mayoría de los estudiantes está de acuerdo en que sí lo hacen. Sin embargo, hay una creciente responsabilidad en búsqueda de información que pasó del 56.1\% antes de la pandemia al 65.4\% durante la pandemia, y esta tendencia continuará a futuro resultando en un $68.8 \%$ de encuestados después de la pandemia. Ello responde a una actitud responsable en el aspecto económico y de salud, porque el comprador asiste a los lugares de compra sabiendo qué quiere comprar y no se expone a buscar por mucho tiempo. Como se ha visto anteriormente, la actitud de conciencia de compra, acompañada de una preocupación por el menor despilfarro de dinero, ha sido común en las distintas partes del mundo en esta crisis. En cuanto a la generación $\mathrm{Z}$, conformada por jóvenes para quienes la tecnología es de suma importancia, utilizan la misma cuando buscan información. Así lo mencionan Fowks y Torrado (2018), «son una generación sobreexpuesta a la información, multipantallas y los primeros en socializar a través de la tecnología» (p. 1).
En cuanto a si, cuando realizan una compra, buscan los descuentos: en general en los tres tiempos se puede ver que es una actitud frecuente en los estudiantes, pero viene en crecimiento con la llegada de la pandemia (hubo un aumento de $1.6 \%$ de las personas que están totalmente de acuerdo con la afirmación) y en especial a futuro. Sin embargo, se aprecia un aumento de $3.2 \%$ en los encuestados que estaban totalmente en desacuerdo durante la pandemia, porque, como se ha visto anteriormente, si bien ha sido frecuente la búsqueda de descuentos, también es usual que en tiempos de crisis se reduzca el consumo. Entonces hay más encuestados que no buscaron descuentos, porque sencillamente no buscaron comprar.

En cuanto a si la calidad es un factor determinante al momento de realizar una compra, en el tiempo anterior a la pandemia el $91.1 \%$ de los encuestados consideraba la calidad como un factor determinante en la compra, durante la pandemia este porcentaje disminuyó a un $87.7 \%$; esto sucede porque se priorizó los 


\section{Figura 3}

Búsqueda de descuentos

Cuándo realiza una compra, busca los descuentos

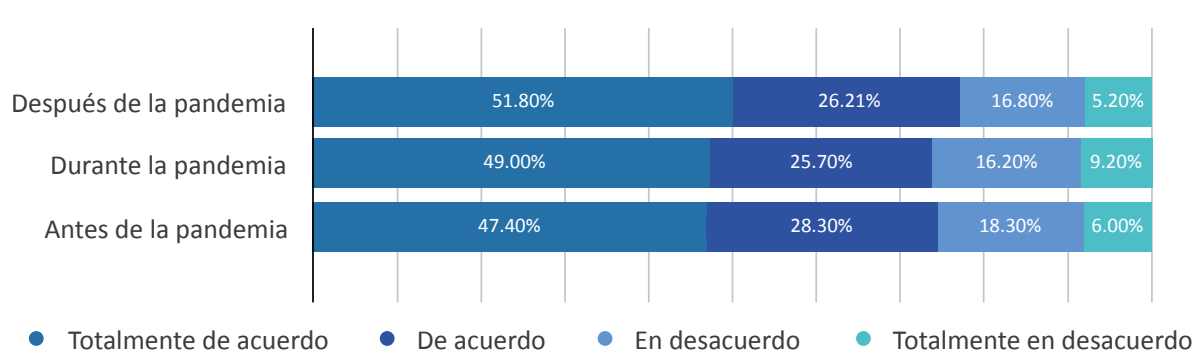

Nota. Elaboración propia.

precios bajos por los recortes económicos y la mayor conciencia del gasto. En tiempos de crisis el precio se convierte en eje de la comunicación, por encima de los valores intangibles de marca [ej. calidad] y de empresa (Fernández et al., 2011, p. 127).

En cuanto a la fidelidad de marca, se preguntó si generalmente cambian de marcas según su conveniencia. Por las múltiples interrupciones de las cadenas de distribución, muchas personas,

\section{Figura 4}

Calidad de un producto

Cuando realiza una compra, la calidad del producto es un factor...

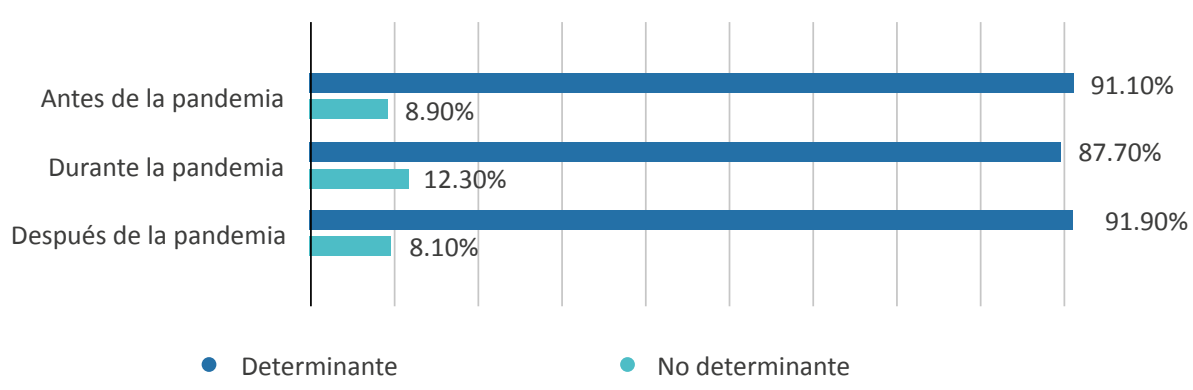

Nota. Elaboración propia. 


\section{Figura 5}

Fidelidad a la marca

En cuanto a sus compras habituales, usted generalmente...

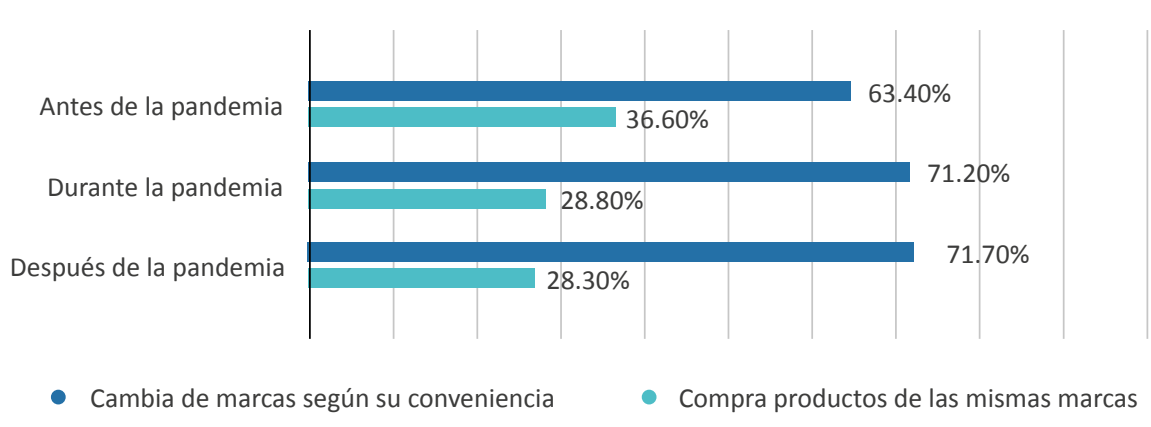

Nota. Elaboración propia.

al no encontrar sus marcas preferidas, optaron por otras. Asimismo, por las restricciones de movilización, muchos también optaron por el cambio de minoristas. Además, se dio un mayor énfasis a las compras en línea. Con todo ello la fidelidad a las marcas disminuyó y los consumidores cambiaron de marcas según su conveniencia. A todo ello se suma el hecho de que hay una mayor sensibilidad a los cambios de precios en las crisis; si una marca alterna tiene un mejor precio, los jóvenes optaron por esa marca. Esta actitud se conservará postpandemia.

En cuanto a las compras electrónicas antes de la pandemia, un $47.1 \%$ de los encuestados no realizó compras por internet. Esta tendencia cambió durante el tiempo de la pandemia, ya que el porcentaje de personas que no compra por internet bajó, en beneficio mayormente de las compras a emprendimientos locales; por otro lado, las compras a grandes y medianas empresas disminuyó en un 5.5\%. La tendencia a comprar por internet a emprendimientos locales se mantendrá para el $41.1 \%$ de los encuestados, y muchos volverán a comprar a grandes y medianas empresas. Como se vio en otras investigaciones, el comercio local pasa a tener mayor relevancia en esta crisis, beneficiando tanto a los productores como a los consumidores. El peruano postcuarentena confirma esto, revelando que muchas personas aumentaron su consumo en línea, ya sea de streaming de entretenimiento o educativo y también de compras en línea (Ipsos, 2020, p. 36). Esto llevó a que incluso se genere un desborde de compras online a grandes y medianas empresas (Bernedo y Hinojosa, 2021). Particularmente en la ciudad de Arequipa el comercio electrónico tuvo uno de los crecimientos más significativos en el país: «El $60 \%$ de todas las provincias ha presentado un crecimiento. Después de Lima, los que han tenido mayor crecimiento son Arequipa, Callao, Piura, Cusco, Trujillo e Ica» (Bravo, 2021, p. 1). En el caso de la generación $\mathrm{Z}$, donde se encuentra gran parte 


\section{Figura 6}

Compras por internet

En cuanto a las compras electrónicas, por redes sociales o páginas web, mayormente usted...

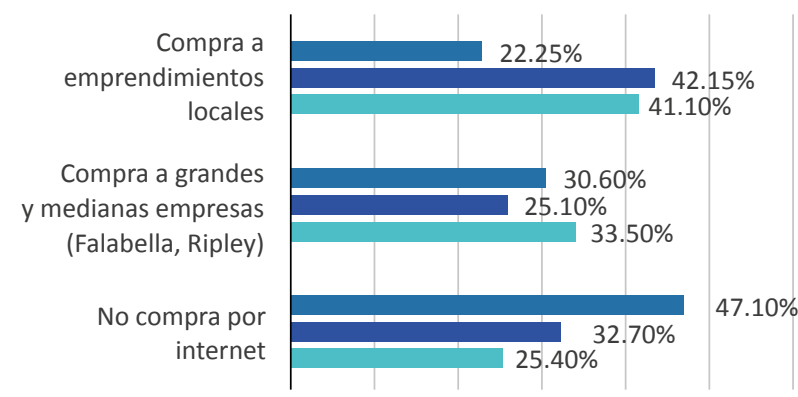

- Antes de la pandemia

- Durante la pandemia

- Después de la pandemia

Nota. Elaboración propia.

\section{Figura 7}

Visitas a centros comerciales

Compra productos en tiendas físicas de especialidad (ejemplo: Coolbox, Illaria) o tiendas físicas por departamento (ejemplo: Saga Falabella, Ripley)

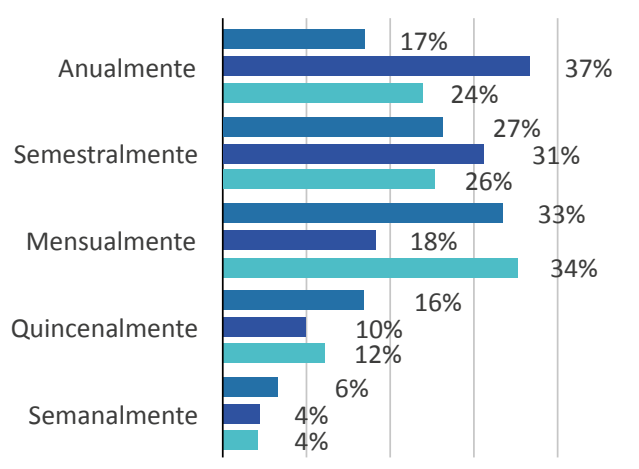

- Antes de la pandemia - Durante la pandemia

- Después de la pandemia

Nota. Elaboración propia. 
de la muestra analizada, por tener más contacto con la tecnología, sus procesos de compra son más online que físicos, prefiriendo comprar de manera digital en diferentes plataformas (Aybar Lindley et al., 2017).

La figura 7 muestra que las personas, antes de la pandemia, acudían mensualmente a tiendas físicas de especialidad en su mayoría (33\%) o semestralmente (27\%). Esto cambió drásticamente durante la pandemia, siendo que el $37 \%$ dijo acudir a tiendas físicas de especialidad de manera anual; mientras que después de la pandemia, en gran medida, volverán a acudir a tiendas físicas de especialidad, como antes de la pandemia (Bernedo y Hinojosa, 2021). Los consumidores evitaron las aglomeraciones por temor al contagio y algunos optaron por las compras en línea. Según el análisis realizado a partir de la encuesta de Deloitte (2021), el 73\% de la generación $\mathrm{Z}$ evitó visitar las tiendas o lugares muy concurridos. Asimismo, se priorizó las compras de primera necesidad. Sin embargo, los jóvenes arequipeños son muy tradicionales, por lo que a futuro volverán a las tiendas, ya sea para probarse la ropa o ver el producto directamente (Bernedo e Hinojosa, 2021).

En cuanto a la necesidad de alimentación, hubo un aumento de la frecuencia en el consumo de comida hecha en casa durante la pandemia, que permanecerá en gran medida después de ella. El consumo es entonces de insumos alimenticios (ingredientes) más que de comidas preparadas. Como se vio en los antecedentes, es una actitud normal el hecho de preparar los alimentos en casa como modo de ahorro económico y, en este caso, también para evitar el contagio.

Pedir comida era la segunda opción más frecuente antes de la cuarentena para $50.79 \%$ de los encuestados; sin embargo, este porcentaje bajó durante la cuarentena a $42.93 \%$ de los encuestados. Para el tiempo posterior a la pandemia, $52.88 \%$ de los encuestados opina que pedir comida preparada será su opción menos frecuente. Esto responde a que la mayoría de jóvenes buscará volver a salir de casa tras tantos meses de confinamiento y socializar como solían hacerlo, e incluso más (Bernedo e Hinojosa, 2021).

La opción de comer fuera de casa fue la menos frecuente; sin embargo, pasada la pandemia, un $45.81 \%$ de los encuestados volverá a recurrir a comer fuera de casa como su segunda opción. Esto sucede porque comer fuera de casa se ha convertido en un escenario poco seguro para la salud, a causa de la pandemia. Sin embargo, pasada la pandemia este cambio de comportamiento no permanecerá, ya que comer fuera es una forma de socializar, sobre todo en el grupo etario de los universitarios (Bernedo e Hinojosa, 2021).

Antes de la pandemia, las compras de artículos de belleza en su mayoría se realizaban mensual o semestralmente. Esto cambió drásticamente durante la pandemia, en que el 39\% mencionó no comprar artículos de belleza. Al parecer, al igual que en anteriores crisis, se priorizaron las compras de primera necesidad. En el caso de las mujeres, el uso de maquillaje ya no era indispensable en tiempos de confinamiento. Con respecto a ello, se puede ver una postergación de la necesidad de autoestima y se cumple la jerarquía en la que no se puede satisfacer una necesidad de orden superior (autoestima), peligrando la satisfacción de las de orden inferior (salud, alimentación). Después de la pandemia, la tendencia se acerca bastante a sus valores anteriores a la pandemia, solo que esta vez las compras de estos artículos serán sobre todo semestrales. Se puede observar que la pandemia sí influyó en este hábito de consumo, en este caso en 


\section{Figura 8}

Modalidad de consumo de alimentos: comida hecha en casa

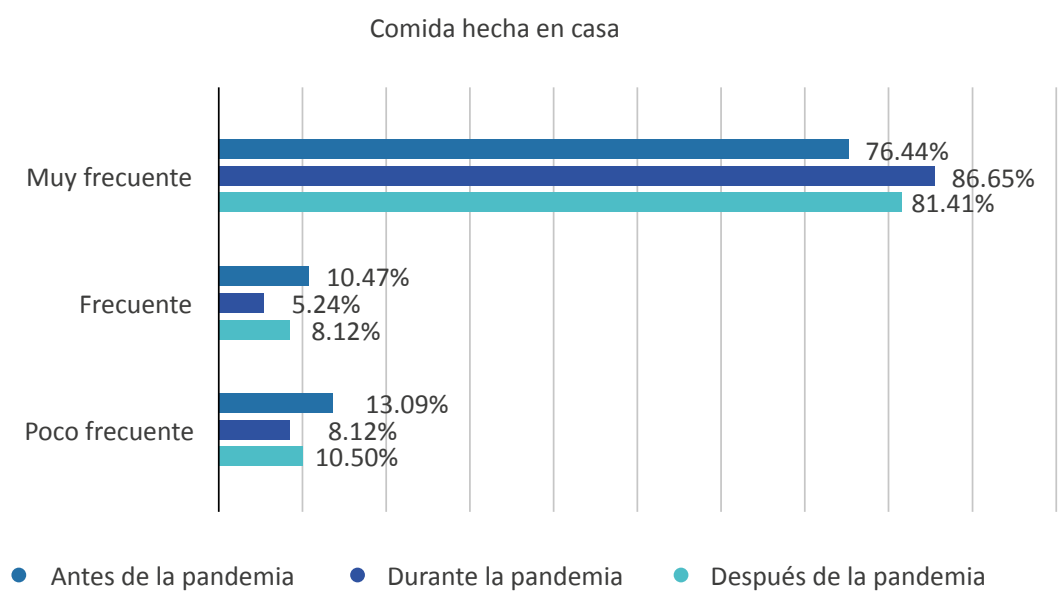

Nota. Elaboración propia.

\section{Figura 9}

Modalidad de consumo de alimentos: pedir comida

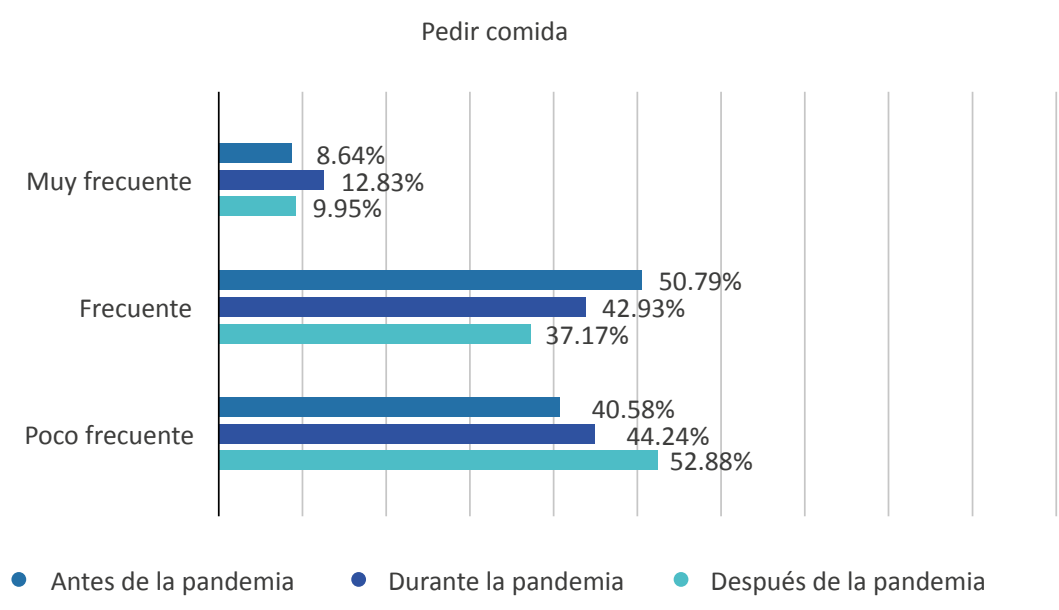

Nota. Elaboración propia. 


\section{Figura 10}

Modalidad de consumo de alimentos: comer fuera

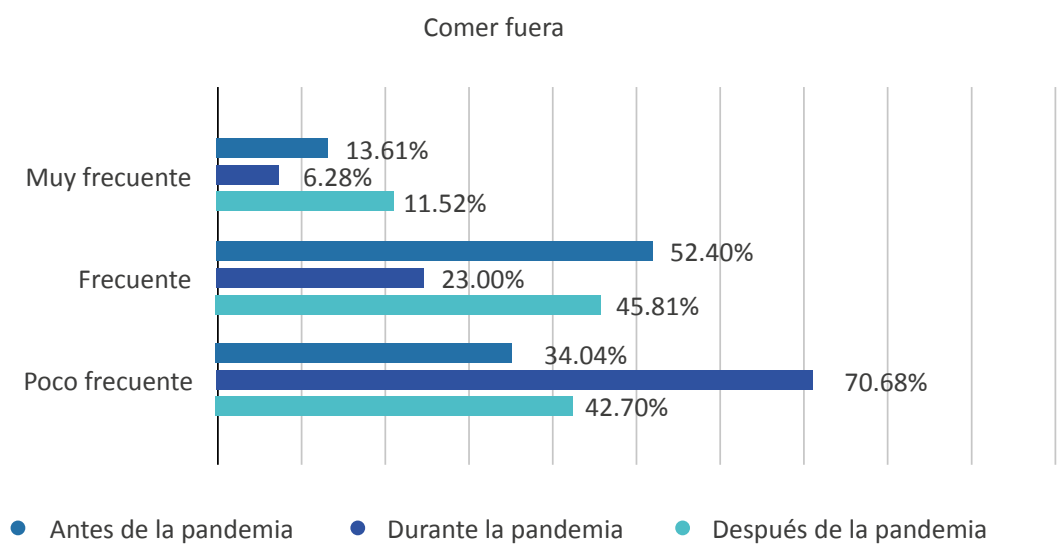

Nota. Elaboración propia.

la frecuencia de adquisición de este tipo de productos (Bernedo e Hinojosa, 2021).

Durante la pandemia, la frecuencia de adquisición de estos artículos bajó respecto al periodo prepandemia, debido a que no son productos de primera necesidad, y su compra podía ser postergada dada la coyuntura económica, las restricciones de la pandemia y la mala distribución de productos. Después de la pandemia, la frecuencia de consumo de ropa y accesorios disminuirá respecto al periodo prepandemia. Esto se puede corroborar con los resultados del estudio del peruano postcuarentena, en el que muchos disminuirán sus gastos en ropa y un $12 \%$ indica que no gastará en esta categoría de productos (Ipsos, 2020).

El presente gráfico revela el tipo de entretenimiento que prefieren las personas. Antes de la pandemia, la mayoría prefería los eventos sociales fuera del hogar. Durante la pandemia, se distingue un cambio abismal de estas costumbres, en las que casi la totalidad de personas (94.76\%) afirmó preferir el entretenimiento dentro del hogar. Para evitar el contagio, muchos recurrieron a juegos en línea, películas o juegos de mesa y evitaron asistir a emplazamientos públicos, incluso después de levantadas las restricciones a restaurantes, parques y cines. Considerando las expectativas para después de la pandemia, la mayoría preferiría entretenerse en casa, por lo práctico y económico. Un $50 \%$ de las personas indica que disminuirá el gasto en entretenimiento fuera del hogar en un mediano plazo (Ipsos, 2020). Se puede apreciar un cambio de comportamiento de consumo en esta categoría de productos y servicios. En este cambio se observa una postergación de las necesidades sociales, prevaleciendo la necesidad básica de la salud como más importante. La generación Z es nativa digital, está inmersa en las redes sociales, 


\section{Figura 11}

Compra de artículos de belleza

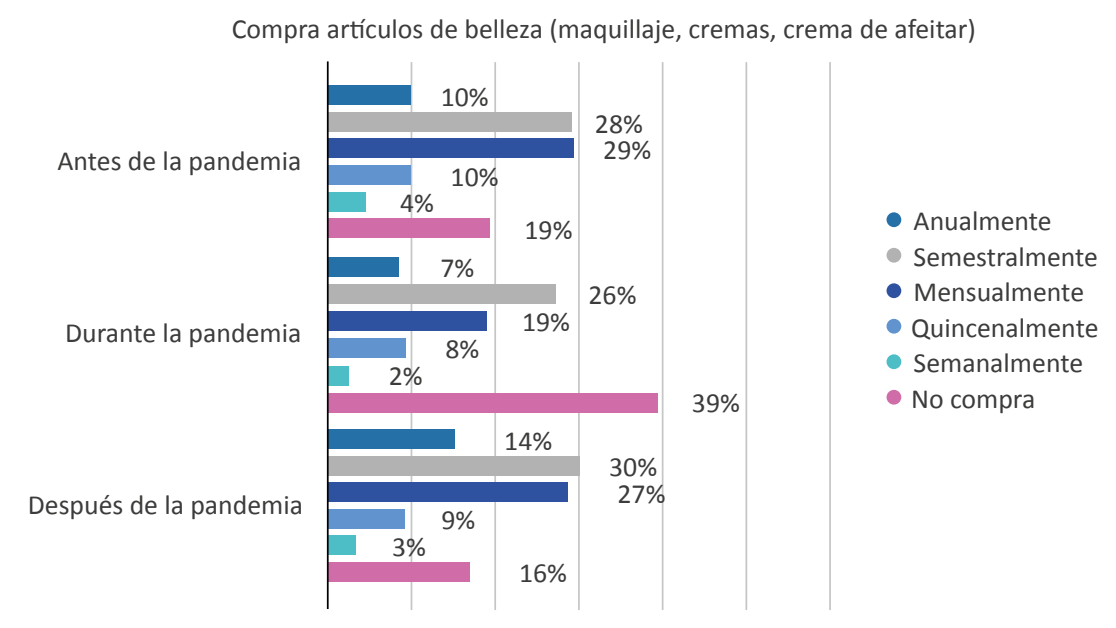

Nota. Elaboración propia.

\section{Figura 12}

Compra de ropa y calzado

\section{¿Con qué frecuencia adquiere nueva ropa o calzado?}

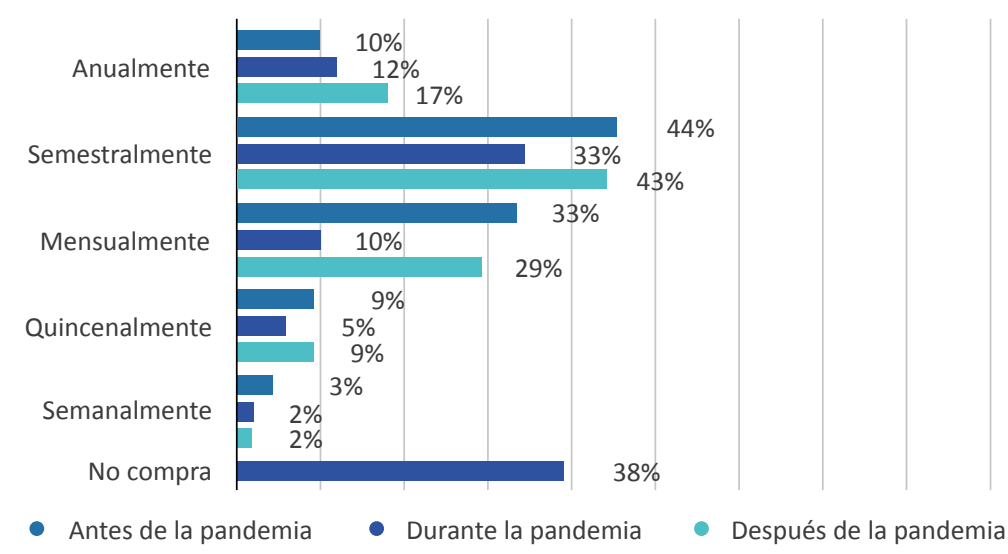

Nota. Elaboración propia. 


\section{Figura 13}

Formas de entretenimiento

¿Qué tipo de entretenimiento consume con mayor frecuencia?

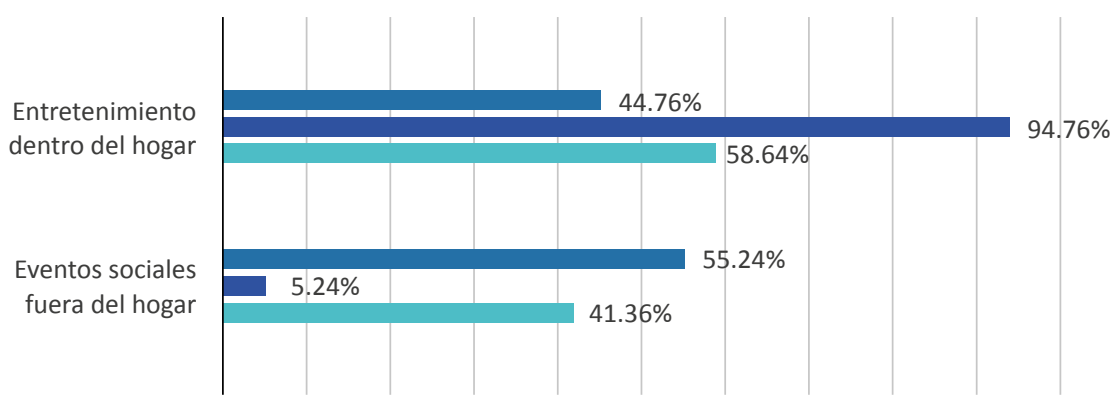

- Antes de la pandemia

Nota. Elaboración propia.

\section{Figura 14}

Realizar viajes dentro o fuera del país

\section{¿Con qué frecuencia realizaba viajes dentro o fuera del Perú?}

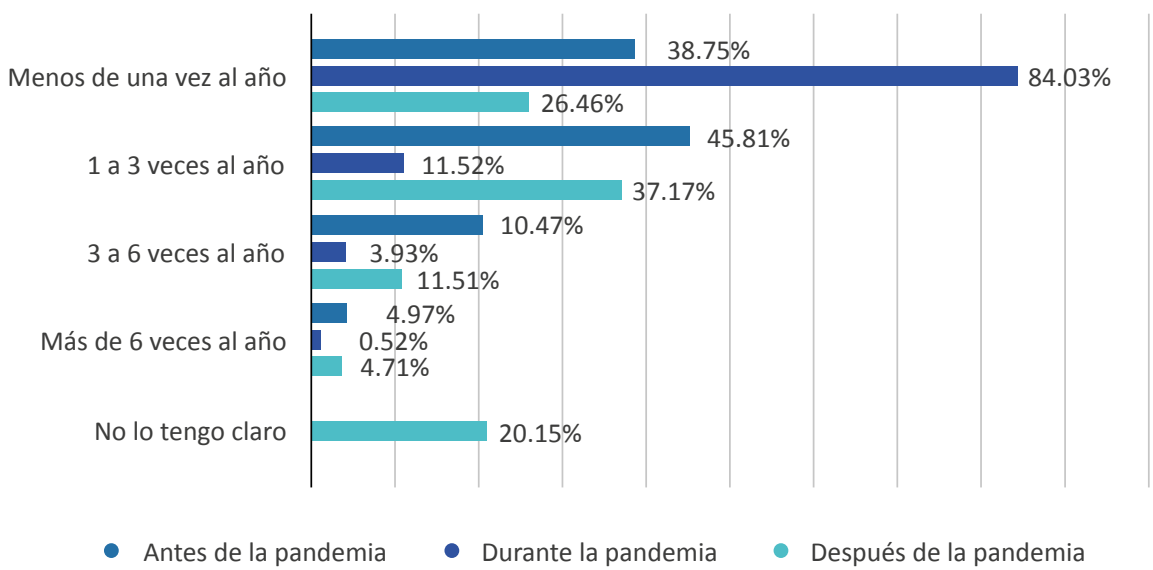

Nota. Elaboración propia. 


\section{Figura 15}

Uso de medios de transporte

Por qué medio se traslada con mayor frecuencia

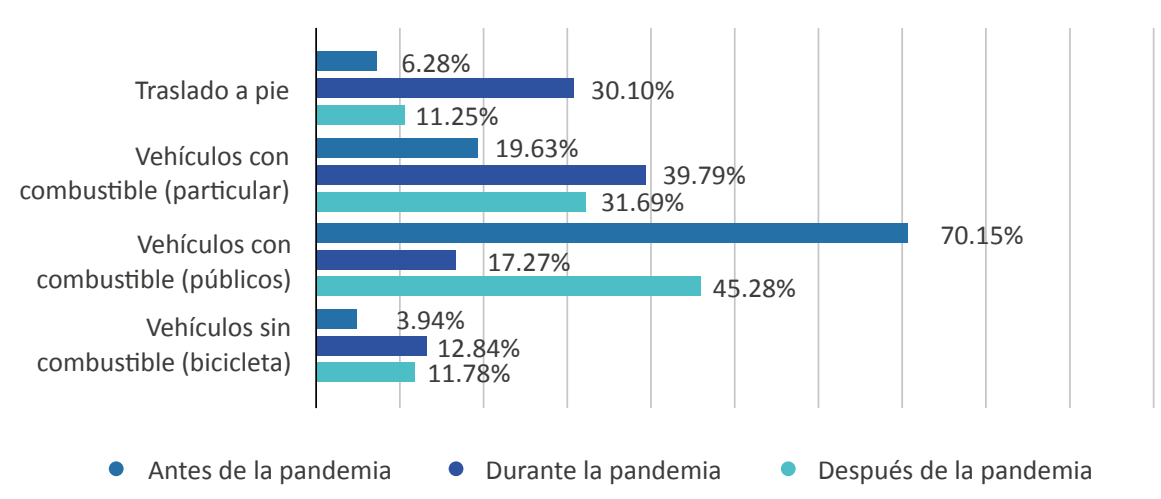

Nota. Elaboración propia.

por lo que usa estas mismas como medio de comunicación de preferencia y se convierten en sus actividades de ocio favoritas. La mayoría de ellos consume contenidos audiovisuales en plataformas, canales y redes sociales virtuales (Moral Pérez et al., 2021). Asimismo, Asimismo, Ipsos (2021) presenta que nueve de cada diez personas de la generación $\mathrm{Z}$ hacen uso de redes sociales y TikTok como entretenimiento.

Antes de la pandemia, la mayoría de personas (45.81\%) realizaba viajes dentro del Perú entre una y tres veces al año; les seguía el grupo de las personas que viajaban menos de una vez al año. Durante la pandemia, la gran mayoría de personas viajó menos de una vez al año, tanto dentro como fuera del Perú, debido a los confinamientos, las restricciones sanitarias, el distanciamiento social y la recesión económica. Después de la pandemia, se ve que el $37.17 \%$ de las personas afirma que seguirá viajando entre una y tres veces al año. Sin embargo, se aprecia que un buen porcentaje de personas afirma que no viajará o que no lo sabe, y esto se debe a que aún existe mucha incertidumbre sobre el futuro. El turismo será uno de los sectores de más difícil retorno (Bernedo e Hinojosa, 2021).

En cuanto al desplazamiento de las personas en el tiempo anterior a la pandemia, un $70.15 \%$ de los encuestados se trasladaba por medio de transporte público. Con la pandemia, el medio de transporte masivo se ha vuelto la opción más peligrosa, sanitariamente hablando, a lo que se añadieron las restricciones que se impusieron a inicios de las primeras cuarentenas; por ello, solo el $17.27 \%$ de los encuestados usó estos medios durante la pandemia, en beneficio de los vehículos particulares, las bicicletas y el traslado a pie. Sin embargo, a futuro estas variaciones tenderán a volver a la normalidad para 


\section{Figura 16}

Inscripción a cursos online

¿Se inscribió en cursos en internet, adicionales a sus estudios universitarios

(Coursera, Crehana, Google, Microsoft, etc)?

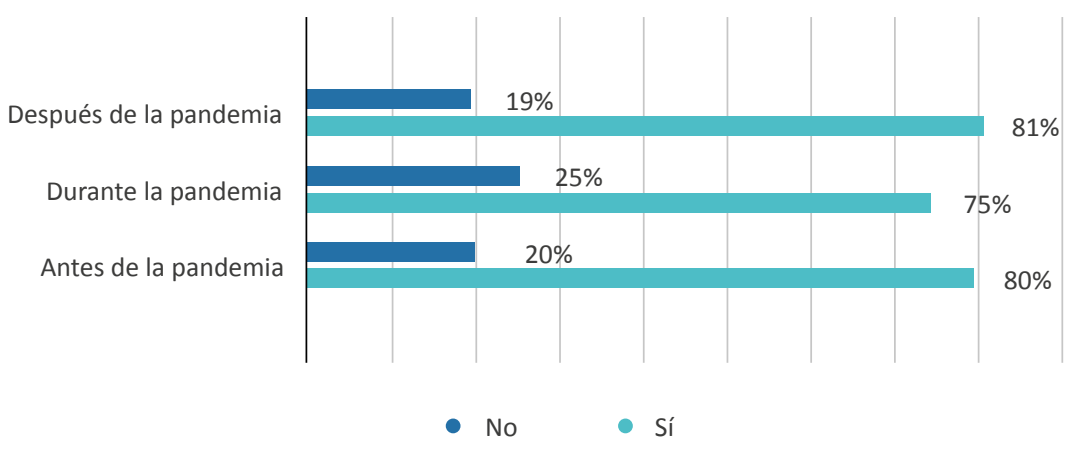

Nota. Elaboración propia.

la mayoría de los encuestados, mas no para un porcentaje de ellos (Bernedo e Hinojosa, 2021).

La crisis de la pandemia trajo nuevos hábitos de consumo y, con respecto al servicio educativo, hubo una gran variación. La mayoría de los encuestados adquirió cursos online adicionales a sus estudios de pregrado durante la pandemia, y se espera que esta tendencia continúe después de ella. Antes de la pandemia, la gran mayoría de jóvenes encuestados no habían contemplado adquirir estos servicios. Se ha dado una adaptación digital que revela la necesidad de autorrealización de los universitarios. Adicionalmente a ello, considerando que ya habían experimentado las clases en línea por un largo tiempo, ya no estaban tan reacios a probar llevar un idioma u otro curso en modalidad virtual (Bernedo e Hinojosa, 2021).

El uso de mascarillas es un hábito que nació con la pandemia; sin embargo, aún después de la pandemia, permanecerá como un comportamiento que quedará arraigado por algún tiempo en la juventud arequipeña. Como lo contextualiza Millán (2020), el uso de mascarillas en pandemia, como en la «gripe española», sirvió para controlar los contagios de mejor manera; por ende, para la juventud arequipeña el uso de mascarillas es una forma de prevenir la enfermedad. En este comportamiento se puede apreciar la gran importancia que se le dio a la satisfacción de la necesidad de salud, la cual antes no era tan notoria para los jóvenes. Durante la pandemia, según Deloitte (2021), el 85\% de peruanos de la generación $\mathrm{Z}$ hizo uso de las mascarillas cuando estaba en público.

Con la pandemia también inició el comportamiento de desinfectar los productos una vez adquiridos; como se aprecia en los gráficos gran porcentaje de los encuestados afirma que, durante y después de la pandemia, continuará 


\section{Figura 17}

Uso de mascarillas

Después de la pandemia, ¿qué tan probable es que al ir a comprar use mascarilla?

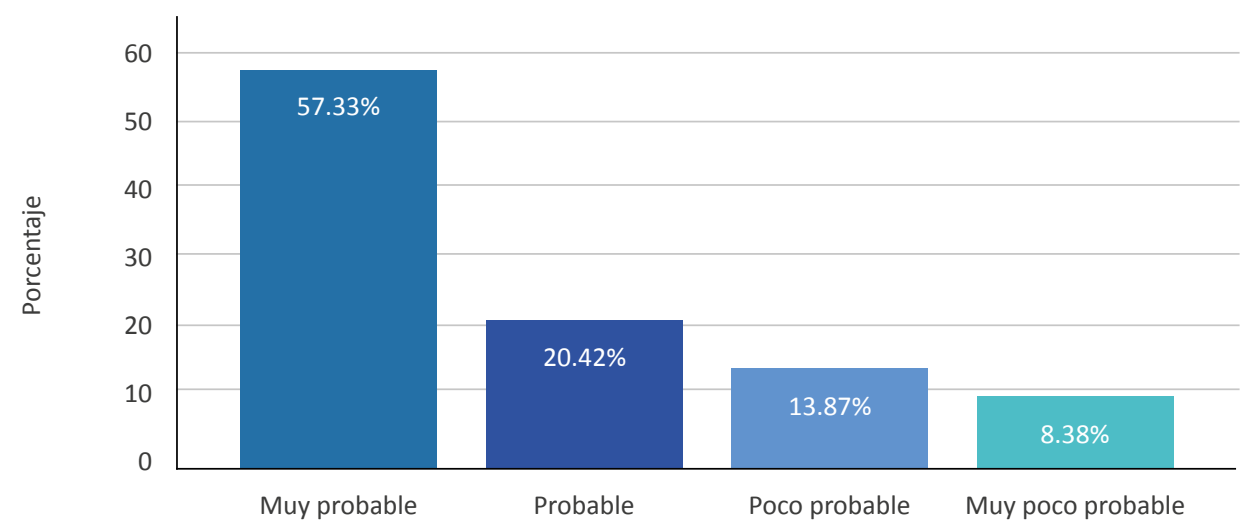

Nota. Elaboración propia.

Figura 18 / 19

Desinfección de productos

Durante la pandemia, ¿desinfecta los productos cuando los adquiere?

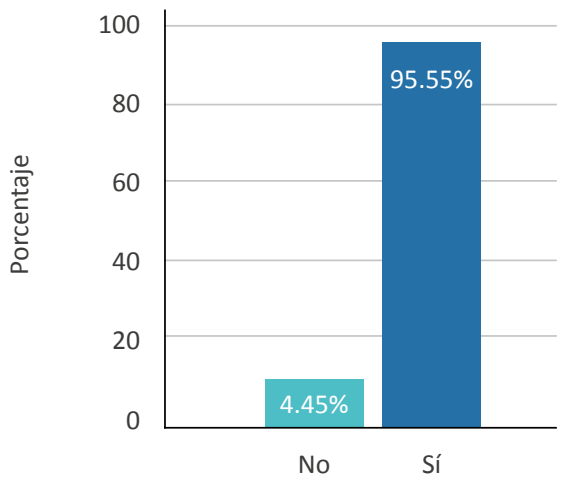

Después de la pandemia, ¿estima que desinfectará los productos cuando los adquiera?

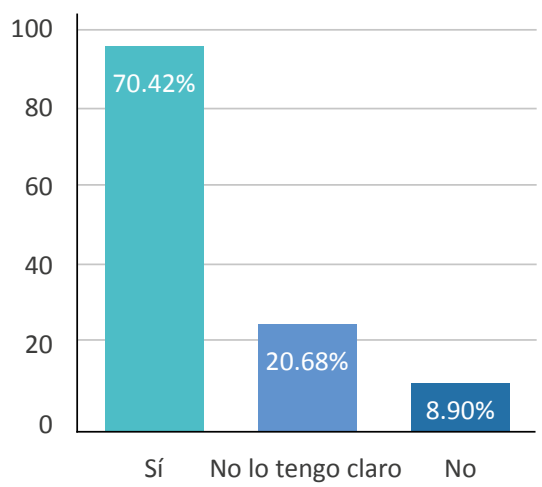

Nota. Elaboración propia. 


\section{Figura 20}

Uso de plásticos y químicos

Durante la pandemia, en comparación con el tiempo anterior, al momento de realizar sus compras, usó plásticos o químicos en...

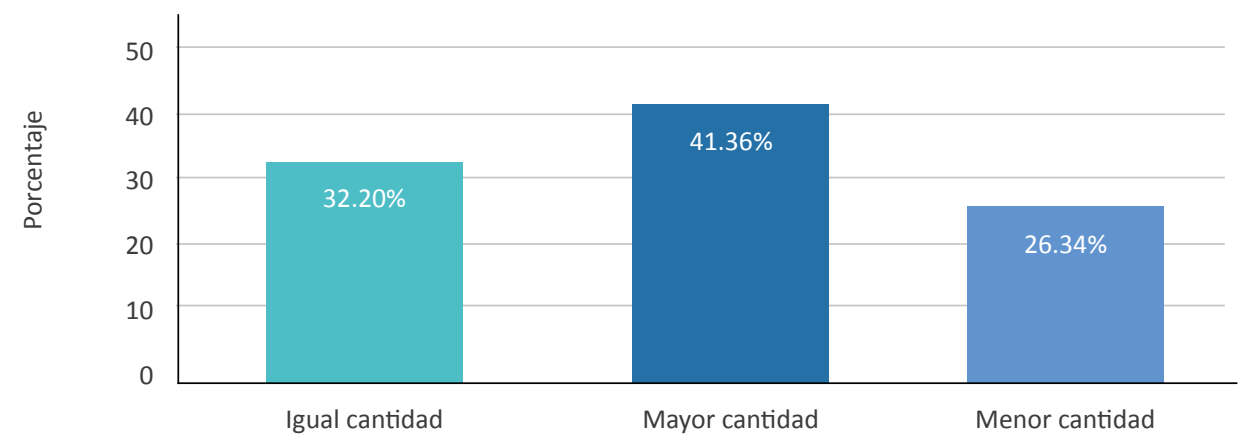

Nota. Elaboración propia.

con el hábito de desinfección de los productos adquiridos, pues aún los consumidores sienten temor y se sienten vulnerables a contraer el virus; por consiguiente, los consumidores son más precavidos y responsables en este tema de la seguridad y la salud.

Durante la pandemia, diferentes emprendimientos, pymes y grandes empresas, para poder seguir operando en el mercado, se han adaptado a las medidas restrictivas señaladas por parte del gobierno. En esta misma línea, se propició el uso de doble, incluso triple, empaque plástico, sin tomar en cuenta las repercusiones en el tema ambiental, y es que los consumidores están preocupados por no contraer el virus. La pandemia también propició el mayor uso de químicos para la desinfección. Un gran porcentaje de los encuestados considera que, durante la pandemia, se empleó mayor cantidad de plásticos de un solo uso, así como químicos de desinfección. Sin embargo, no todos consideran que el tema ambiental haya empeorado con la pandemia. Según Deloitte (2021), el 85\% de la generación $Z$ considera que los cambios en el ambiente durante la pandemia los hacen ser más optimistas de que el cambio climático pueda revertirse; de la misma forma el 51\% considera que, si las personas se comprometen personalmente con el medio ambiente, habrán mejorado después de la pandemia.

\section{Conclusiones}

A partir de la investigación se concluyó que sí existe una influencia de la crisis provocada por el Covid-19 en los hábitos de consumo de los universitarios arequipeños en cuanto a las categorías de productos, actitud de compra, lugar de compra y las necesidades del consumidor. 
Antes de la pandemia del Covid-19, los hábitos de consumo de los estudiantes arequipeños se caracterizaban por una actitud de compra menos racional en cuanto a la búsqueda de información, valor real de productos y fidelidad de marca. Los consumidores estaban guiados por necesidades que moldeaban su adquisición de productos y servicios esenciales y no esenciales. El consumo se realizaba en un entorno físico, así como el entretenimiento fuera del hogar. Existía un bajo interés por el uso de educación virtual adicional a los estudios de pregrado, mientras que los medios de transporte más utilizados eran los vehículos públicos y privados.

Durante la pandemia del Covid-19, los hábitos de consumo de los estudiantes arequipeños se caracterizaron por una actitud de compra más racional en cuanto a la búsqueda de información, valor real de productos y fidelidad de marca. Los consumidores brindaron mayor importancia a la salud y menor importancia a las necesidades sociales y de autoestima, lo que ocasionó un descenso de consumo de productos y servicios no esenciales. Se dio mayor importancia al canal virtual. En cuanto a las categorías de productos, se incrementó el consumo de entretenimiento dentro del hogar, mayor uso de educación virtual adicional a los estudios de pregrado, y los medios de transporte más utilizados fueron los vehículos privados y el traslado a pie.

Se prevé que, una vez controlada la pandemia del Covid-19, los hábitos de consumo de los estudiantes arequipeños se caracterizarán por una actitud de compra racional en cuanto a la búsqueda de información, al valor real de los productos y la fidelidad de la marca. Habrá un retorno al consumo de productos esenciales y no esenciales, con variaciones en el mayor consumo de insumos alimenticios. Las compras por internet se afianzarán como un hábito permanente, pero las compras presenciales no perderán importancia. En cuanto a las categorías de productos, la compra de ropa y servicios de viajes volverán a la frecuencia anterior a la pandemia. En cuanto a los productos y servicios de belleza, la menor frecuencia de consumo se afianzará como hábito. La preferencia de entretenimiento dentro del hogar y la adquisición de cursos online permanecerán como hábitos, y el medio de transporte más utilizado volverá a ser el transporte público y privado.

\section{Referencias bibliográficas}

Abdelnour, A., Babbitz, T. y Moss, S. (1 de mayo de 2020). Pricing in a pandemic: Navigating the COVID-19 crisis. McKinsey \& Company. En https://mck.co/3nYkP1j

Adyel, T. (11 de septiembre de 2020). Accumulation of plastic waste during COVID-19. Science, 369(6509), 1314 1315. En https://www.science.org/doi/full/10.1126/science.abd9925

Althaus, S. L. (2014). American News Consumption during Times of National Crisis. American Political Science Association, pp. 517-521. 
Armas, A. (2016). Dolarización y desdolarización en el Perú. En: G. Yamada y D. Winkelried (eds.). Política y estabilidad monetaria en el Perú. (pp. 61-94). Lima: Universidad del Pacífico.

Banco Central de Venezuela [BCV]. (2018). Producto Interno Bruto. http://www.bcv.org.ve/estadisticas/productointerno-bruto

Bermúdez, Y., Mazuera-Arias, R., Albornoz-Arias, N. y Morffe, M. (2018). Informe sobre la movilidad humana venezolana. Realidades y perspectivas de quienes emigran. Servicio Jesuita a Refugiados; Universidad Católica del Táchira; Universidad Simón Bolívar.

Briones, G. (2003). Métodos y técnicas de investigación para las ciencias sociales. Trillas.

Canales, A. I. (2017). La migración internacional en los modelos neoclásicos. Una perspectiva crítica. Huellas de la Migración, 2(3), 11-36.

Carassou, R. H. (2006). La perspectiva teórica en el estudio de las migraciones. Siglo Veintiuno Editores.

Chacaltana, J. (2016). Perú, 2002-2012: crecimiento, cambio estructural y formalización. Revista Cepal (119), 47-68.

Crasto, T. C. y Álvarez, M. R. (2017). Percepciones sobre la migración venezolana: causas, España como destino, expectativas de retorno. Migraciones. Publicación del Instituto Universitario de Estudios sobre Migraciones (41), 133-163.

ENCOVI. (2017). Encuesta de Condiciones de vida de Venezuela. Caracas: Universidad Andrés Bello, Universidad Central de Venezuela, Universidad Simón Bolívar. https://www.ucab.edu.ve/wp-content/uploads/ sites/2/2018/02/ENCOVI-2017-presentaci\%C3\%B3n-para-difundir-.pdf

Garavito, C. y Muñoz, I. (eds.) (2012). Empleo y protección social. PUCP.

García Abad, R. (2003). Un estado de la cuestión de las teorías de las migraciones. Historia Contemporánea, 26, 329-351.

Arora, N., Robinson, K., Charm, T., Grimmelt, A., Ortega, M., Staack, Y., ...y Yamakawa, N. (8 de julio de 2020). El sentimiento y el comportamiento del consumidor continúan reflejando la incertidumbre de la crisis del COVID-19. McKinsey y Company. Recuperado el 8 de octubre de 2020, de https://cutt.ly/ZmWA9FA

Aybar Lindley, L., Colchado Pisconti, D., Chávez Aguilar, F., Gonzales Benavides, S. y Obando Ponce, O. (2017). El comportamiento del consumidor de la generación z respecto al proceso de compra tradicional y su relación con las marcas en los medios digitales. Universidad Peruana de Ciencias Aplicadas. Recuperado el 22 de octubre de 2021, de https://bit.ly/3B9u81F

Barrera, V., Luna, S. y Molano, J. P. (2020). Oportunidades de emprendimiento en Bogotá originadas por cambios de hábitos de consumo debido a la pandemia. Bogotá: Universidad EAN. En https://cutt.ly/zmWA5yy

Bernedo Gómez, N. e Hinojosa Paz, S. (2020). Influencia de la crisis COVID-19 en los hábitos del consumo de estudiantes universitarios Arequipa-2020. Tesis de Pregrado. Arequipa, Arequipa, Perú: Universidad Católica San Pablo. Recuperado el 24 de junio de 2021, de https://cutt.ly/RmWSqYc 
Bravo, F. (13 de marzo de 2021). Comercio electrónico en Perú: La Guía más completa del mercado. ECOMMERCENEWS. En https://www.ecommercenews.pe/ecommerce-insights/2021/crecimiento-delcomercio-electronico-en-peru.html

Damián, A. (2015). Crisis global, económica, social y ambiental. Estudios Demográficos y Urbanos, XXX, pp. 159-199. En http://www.scielo.org.mx/pdf/educm/v30n1/0186-7210-educm-30-01-00159.pdf

Deloitte (2021). Encuesta Millennial y Gen Z 2021. Análisis. Perú.

Euromonitor International (2020). The coronavirus era: How consumers shop. https://www.portal.euromonitor. com/portal/analysis/tab\#

Fernández Blanco, E., Alameda García, D. y Martín, I. (2011). Las estrategias publicitarias de las marcas en el contexto de crisis. adComunica. Revista de Estrategias, Tendencias e Innovación en Comunicación, I, 119-138. En http://www.adcomunicarevista.com/ojs/index.php/adcomunica/article/view/12

Fischer de la Vega, L. y Espejo Callado, J. (2011). Mercadotecnia (4.a edición). México: McGraw-Hill/Interamericana Editores, S.A.

Fowks, C. y Torrado, U. (2018). Generación Z. La nueva generación en formación. Datum. Recuperado el 22 de octubre de 2021, de https://www.datum.com.pe/new_web_files/files/pdf/GeneracionZ.pdf

Gallego, M. (22 de junio de 2020). CincoDías. Recuperado el 8 de octubre de 2020, de https://bit.ly/3ACRkWk

Gundel, S. (2005). Towards a New Typology of Crises. Journal of Contingencies and Crisis Management, XIII, pp. 106-115.

Hernández Sampieri, R., Fernández Collado, C. y Baptista Lucio, P. (2014). Metodología de la investigación: Roberto Hernández Sampieri, Carlos Fernández Collado y Pilar Baptista Lucio (6.a ed.). México D.F.: McGraw-Hill.

Herrero Ortiz, J. (2007). Monólogo de un vendedor: 5 temas de marketing integral técnico empresarial. Madrid: Ediciones Díaz de Santos, S.A. Recuperado el 28 de septiembre de 2020.

Huang, X., Kuijpers, D., Li, L., Sha, S. y Xia, C. (6 de mayo de 2020). How Chinese consumers are changing shopping habits in response to COVID-19. McKinsey \& Company. En https://mck.co/3Elh1HB

International Labour Organization (2020). World Employment and Social Outlook - Trends 2020. En https://www. ilo.org/global/research/global-reports/weso/2020/lang--en/index.htm

Instituto Peruano de Economía. «Pobreza Creció a 31\% en Las Regiones Del Sur Por La Pandemia | Instituto Peruano De Economía». En www.ipe.org.pe, 8 June. 2021, https://bit.ly/3INxxgJ

IPSOS (2020). El peruano postcuarentena. Lima: Ipsos.

IPSOS (2021). Generaciones en el Perú 2020. Ipsos, Perú. Recuperado el 22 de octubre de 2021, de https://www. Ipsos.com/es-pe/generaciones-en-el-peru-2020

Lara, I. y Ortega, I. (diciembre de 2016). Los consumidores de la Generación Z impulsan la transformación digital de las empresas. Revista de Estudios de Juventud (114), pp. 71- 82. En https://dialnet.unirioja.es/servlet/ articulo?codigo $=6118377$ 
Medina, A. (10 de julio de 2020). Expansión. En https://bit.ly/3lOcwmi

Millán, A. (17 de julio de 2020). Coronavirus: por qué los japoneses utilizaban mascarillas mucho antes de la aparición del covid-19. BBC News Mundo. En https://www.bbc.com/mundo/noticias-53398040

Mitroff, I. y Alpaslan, M. (2003). Preparándose para el mal. Harvard Business Review. En https://hbr.org/2003/04/ preparing-for-evil

Moral Pérez, E., Guzmán Duque, A. y Bellver Moreno, C. (2021). Consumo y ocio de la Generación Z en la esfera digital. Prisma Social (N. $\left.{ }^{\circ} 34\right)$, pp. 88-105.

Moreno, E. (2008). Gestión de la información y la comunicación en emergencias, desastres y crisis sanitarias. Revista de la Sociedad Española de Medicina de Urgencias y Emergencias, XX, pp. 117-124. En https:// dialnet.unirioja.es/servlet/articulo?codigo=2580937

Ordaz-NeÂmeth, I., Arandjelovic, M., Boesch, L., Gatiso, T., Grimes, T. y Hjalmar S. Kuehl, M. L. (2017). The socioeconomic drivers of bushmeat consumption during the West African Ebola crisis. PLOS neglected tropical diseases, pp. 1-22. En https://bit.ly/3pocXql

Quarantelli, E. (1993). Community Crises: An Exploratory Comparison of the Characteristics and Consequences of Disasters and Riots. Blackwell Publishing Ltd, I, pp. 67-78.

Quelart, R. (26 de junio de 2020). La Vanguardia. Recuperado el 8 de octubre de 2020, de https://bit.ly/3kztB44

Quintanilla, I., Luna, R. y Berenguer, G. (1998). La compra impulsiva y la compra patológica: el modelo CAC.

Sagara, N., Mellado, R. y Rojas, P. (2020). Los comportamientos que cambian después del confinamiento. Lima: IPSOS. En https://bit.ly/3EFWXWh

Shaluf, I., Ahmadun, F. y Mat, A. (2019). A review of disaster and crisis. Disaster Prevention and Management: An International Journal, pp. 24-32.

Solana, J. (26 de agosto de 2020). El impacto del COVID-19 en los hábitos de entretenimiento de los mexicanos. EY México. Recuperado el 8 de octubre de 2020, de https://go.ey.com/2ZirjOl

Suito, J. (2020). Los estudiantes usan más maquillaje y tratamientos faciales que aquellos que trabajan. Mercado Negro, pp. 1-3. En https://www.mercadonegro.pe/marketing/millennials-peruanos-preocupan-cadavezmás-apariencia/

Wright, O. y Blackburn, E. (28 de abril de 2020). Accenture. Recuperado el 05 de octubre de 2020, de https:// accntu.re/3wsqEoz

Zierlein, T., Garbe, C., Freesemann, M.-L., Naumann, L. y Maag, V. (2020). Impact of the Covid-19 crisis on shortand-medium-term consumer behavior. Monitor Deloitte, 48. Recuperado el 5 de octubre de 2020, de https://cutt.ly/dmWSrYp 